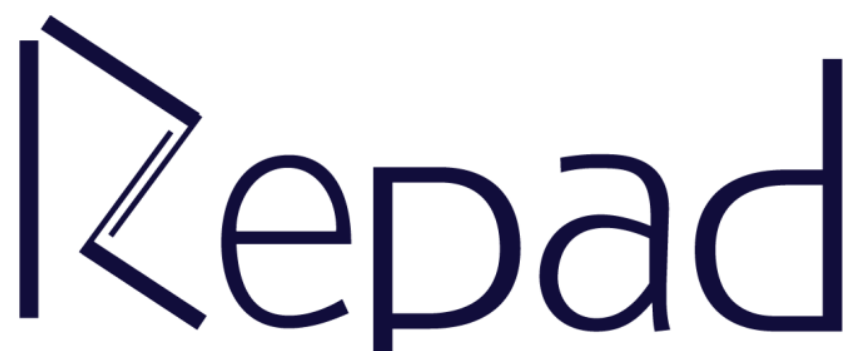

Vol. 3, n. 1, Abril/2019

Revista Estudos e

Pesquisas em Administração

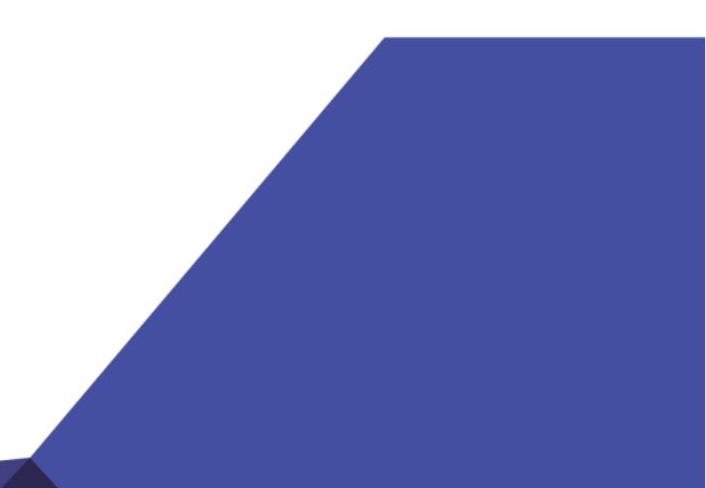




\title{
REFLEXÕES SOBRE AS CONTRIBUIÇÕES DA AUDITORIA CONTÁBIL NO COMBATE A CORRUPÇÃO
}

\author{
Edir Vilmar Henig \\ Universidade de Coimbra \\ http://orcid.org/0000-0002-8191-1935
}

\begin{abstract}
RESUMO
Tanto os regimes ditatoriais, quanto aos períodos tidos como democráticos tiveram um nível de corrupção acentuado, mas no caso das ditaduras, o autoritarismo impedia que investigações fossem realizadas, já no período democrático tivemos a queda de um presidente envolvido com corrupção. Mesmo com todas estas situações a corrupção não se esvaiu ao contrário, se aperfeiçoou e ganhou novos formatos, estes com mais dificuldade de serem detectados. Neste sentido, a auditoria, que é um ramo da contabilidade, assume papel fundamental no combate a este problema estrutural brasileiro, que apensar de ser possível sua identificação desde seus primórdios, ainda hoje acentua as mazelas sociais mais graves da sociedade e é encontrada em todos os níveis sociais, seja na esfera pública ou privada. Para este trabalho utilizamos análise documental como Leis e normatizações, e levantamento bibliográfico para fomentar a discussão em torno da temática. Tendo como objetivo básico, analisar a importância da auditoria na prevenção, identificação e combate da corrupção.
\end{abstract}

Palavras Chave: Corrupção. Auditoria. Administração Pública.

\section{REFLECTIONS ABOUT CONTRIBUTIONS ACCOUNTANT AUDIT IN COMBAT OF THE CORRUPTION}

\begin{abstract}
Both the dictatorial regimes and the periods considered democratic had a marked level of corruption, but in the case of dictatorships, authoritarianism prevented investigations were carried out, even in the democratic period we had the fall of a president involved with corruption. Even with all these situations corruption did not disappear in the opposite direction, it has improved and gained new formats, these with more difficulty to be detected. In this sense, audit, which is a branch of accounting, assumes a fundamental role in combating this Brazilian structural problem, which, if it is possible to identify it from its beginnings, still today accentuates the most serious social problems of society and is found in all social levels, whether in the public or private sphere. For this work we use documentary analysis as Laws and norms, and bibliographical survey to foment the discussion around the thematic one. With the basic objective of analyzing the importance of auditing in the prevention, identification and combat of corruption.
\end{abstract}

Keywords: Corruption. Audit. Public administration. 


\section{INTRODUÇÃO}

Quando refletimos sobre a história brasileira, desde seus primeiros colonizadores, e ao traçarmos um percurso histórico para o pensamento crítico da realidade, podemos perceber que a presença do clientelismo, e favorecimento ilícito, através do poder ou de ocupação de cargos privilegiados dentro do Estado, utilizam desta forma de subterfúgios para alcançar os interesses próprios.

Quando o Estado passou para as mãos de governantes autoritários, além de não haver transparência na gestão, o clientelismo e o forte favor estatal, as investigações e a luta para coibir estes problemas eram inexistentes, e o Estado tinha um caráter paternalista, elitista e neste sentido, não oferecia mecanismo de fiscalização e punição para os corruptos e corruptores.

Considerado uma nação em desenvolvimento e já participante do cenário econômico mundial como protagonista, o Brasil ainda necessita tratar de mazela sociais graves, como a injustiça social, a desigualdade, a miséria e neste sentido, observa-se que ao passo que uma parcela da sociedade goza de nível de vida elevado outra parte vive na miséria, privada até mesmo do básico para sua sobrevivência, e é neste ponto que a desigualdade se manifesta.

Com a queda do regime militar, a redemocratização, e a promulgação Constituição Federativa do Brasil - $\mathrm{CF} / 88$, o termo democracia passou a estar na cena pública e emergiu a preocupação com a eficiência e eficácia dos serviços públicos oferecidos a sociedade, para isso o controle social ganha destaque junto a administração pública.

Ressurge no Estado democrático as garantias individuais preconizadas pela nova Constituição, direitos que ampliam os horizontes para a participação da sociedade na decisão da administração pública, desta forma, temos a transição de um modelo burocrático para um gerencial no qual a eficiência e economicidade tornam-se primordiais para os atos governamentais, não mais bastando fazer o constante na lei, mas para além disto, fazer valer a lei.

É nos anos de 1990, que então, o mundo como um todo passa a ter a percepção ou passa a ver a corrupção como um problema social grave, e que acentua ainda mais as mazelas já existente, e neste sentido, a Organização das Nações Unidas começa a intermediar e trabalhar no sentido de reduzir e combater a corrupção no mundo, estabelecendo diretrizes para que este enfrentamento se execute.

A corrupção traz consigo situações muito negativas, razão está, que não medem forças para combater e punir, e isso é o que torna pertinente saber que instrumentos existentes são constantemente utilizados para reduzir suas consequências através de sua eliminação no seio da sociedade, e nesta perspectiva a Auditoria surge como um instrumento importante e nomeadamente no que se refere a prevenção e o combate à corrupção no setor da Administração Pública.

Nesta perspectiva é importante responder o questionamento que baliza as reflexões que dão sentido a este texto, se a auditoria é um instrumento capaz de contribuir para o combate à corrupção na administração pública brasileira?

A partir da questão balizadora, é elaborado então o objetivo que de forma geral será o que orientará o texto, que é, buscar a compreensão do fenômeno chamado corrupção e os seus impactos que ela traz à sociedade. Para responder esta proposta, é utilizada a metodologia materialista dialética, que analisa o fenômeno interligado com todo o sistema ao qual pertence e que, encontra-se em constante movimento. $\mathrm{O}$ materialismo dialético auxilia nas análises dos fenômenos que segundo, Richardson (2017, p. 38) são interligados com todos os sistemas ao qual pertence e que se encontra em constante movimento. Sendo assim, será feito um aporte histórico e filosófico para perceber o fenômeno da corrupção na construção das estruturas 
sociais, econômicas e políticas do país ao longo da história, sendo que estes processos estabelecem consequências à contemporaneidade, utilizando-se de reflexões teóricas que contribuem para a formulação de novas interpretações da realidade.

Neste sentido, o que justifica a relevância do debate deste tema é a atual situação dos escândalos pelos quais o Brasil tem passado, e demonstra que a Auditoria é um instrumento poderoso para a solução deste problema que envergonha a nação, e desta forma, cada vez mais entender o papel do cidadão no processo de governança participativa e para que a transparência pública alcance a sociedade como um todo.

\section{A CORRUPÇÃO NO ESTADO BRASILEIRO: Origens, desenvolvimento e atualidades}

A palavra corrupção tem suas origens do latim, da palavra corruptione, estando presente também nas línguas francesa, italiana, espanhola, e uma variação similar para o inglês, e tem como sinônimos decomposição, putrefação, depravação, desmoralização, sedução e suborno, neste sentido, sua significação está intrínseca a tudo que é mal, imoral e antiético.

Geralmente o ato de corrupção é atrelado a alguma prática ilegal, onde dois, ou mais agentes, corrupto/s ou corruptor/res executam algumas ações que a lei prescreve como crime, envolvendo a obtenção de propinas, interesses próprios, favores, entre outras coisas que podem caracterizar o ato, desta formo como destaca Silva $(1995$, p. 8), "[...] o senso comum identifica a corrupção como um fenômeno associado ao poder, aos políticos e às elites econômicas", muito embora, considera a corrupção algo frequente entre servidores públicos, e que caracterizam o uso do pequeno poder que possuem para obter recursos, favores dos que infringem a lei.

Podemos afirmar que a corrupção pode ser reconhecida como a expressão da realidade da má gestão das instituições e organizações públicas, e tem se manifestado no decorrer do tempo mediante as variações setoriais e da capacidade de expansão das relações sociais e institucionais, e das esferas públicas e privadas, e ainda podemos salientar e trazer para o debate a afirmação que a corrupção é um dos grandes problemas da que emergem da administração pública brasileira atual.

A partir deste ponto, precisamos enfatizar que ao discutirmos a corrupção não falamos apenas das questões legais, mas também refletirmos outras facetas da ação de defraudar ou infringir a lei, e neste aspecto destacamos a moralidade, a probidade, ética e interesse público. A moralidade é uma característica humana, e em todos os atos dos seres humanos são encontrados consequências e reflexos na ordem social, desta forma, a atividade pública não pode prescindir de uma qualificação moral, sendo, pois, a corrupção o lado avesso daquilo que deve ser a postura ética do agente público.

Antes de prosseguirmos precisamos buscar ajuda da filosofia para entender o que é a moralidade e o que é a ética, neste sentido, buscamos em Chauí (2000) para delimitar o campo da moral que para esta autora são "valores concernentes ao bem e ao mal, ao permitido e ao proibido, e à conduta correta, válidos para todos os seus membros", e ainda estabelece que por ética podemos entende que é "constituído pelos valores e pelas obrigações que formam o conteúdo das condutas morais, isto é, as virtudes".

No entanto, a simples existência da moral não significa a presença explícita de uma ética, entendida como filosofia moral, isto é, uma reflexão que discuta, problematize e interprete o significado dos valores morais. Podemos dizer, a partir dos textos de Platão e de Aristóteles, que, no Ocidente, a ética ou filosofia moral inicia-se com Sócrates (CHAUI, 2000, p. 436). 
A corrupção não é um fenômeno de fácil compreensão, apesar de tão corriqueiramente tratada nas no cotidiano dos telejornais, nas páginas dos jornais impressos, discussões acadêmicas, rodas de bate papo informal, tendo várias facetas e características, e acabam por serem tratadas de forma simplista, porém, a corrupção metamorfoseia dia após dia, obtendo cada vez mais características modernas e mais difíceis de classifica-las, tornando mais difícil para o auditor identificá-las.

Isto acontece por diversas razões: Primeiro porque as transações corruptas impõem aos seus participantes um severo comprometimento com o sigilo, ou seja, quanto mais alto o cargo, o prestígio dos atores, e os valores financeiros envolvidos na transação, maiores também são as exigências de sigilo. Segundo porque os agentes envolvidos informam-se previamente sobre os possíveis riscos e benefícios presentes em cada transação corrupta, pois estão cientes que para gozarem o completo usufruto dos benefícios, é necessário que os riscos sejam, tanto quanto possíveis, eliminados. Assim sendo, as transações corruptas são planejadas e orquestradas no sentido de manter no anonimato e na isenção de toda e qualquer responsabilidade, os seus principais participantes e mentores (PAZ, 2014, p. 19).

Para além disso, todas as transações que envolvem corrupção são relações sociais que se baseiam na confiança e na informalidade, estas "trocas" se realizam, na maior parte das vezes, e se trata de um ambiente de troca de favores baseados na anuência e na confiança mútua, e para isso o sigilo é fundamental.

A corrupção é uma ação livre, onde os agentes participantes fazem esta escolha, se assim não fosse, se caracterizaria como extorsão, outro crime e claramente definido pela legislação brasileira e passível de punição, conforme o artigo 158 do Código Penal brasileiro, desta forma, para que a corrupção, são necessários no mínimo dois agentes e um objetivo elementos: o corruptor e o corrompido, e o objetivo é a vantagens almejadas.

[...] a participação de um agente privado não é obrigatoriamente necessária para configurar a corrupção, pois uma transação corrupta poder ocorrer também entre dois agentes do Estado com o intuído de adquirir poder político, vantagens partidárias, status, reconhecimento ou a manutenção do poder político familiar por meios nepotistas. Nestes casos, a corrupção e o jogo político legítimo tornam-se quase que indistinguíveis. Entretanto, dependendo da noção de corrupção adotada, os componentes podem ser outros. Nas definições que reduzem o conceito de corrupção unicamente aos casos de propina, por exemplo, os elementos são; O agente público, o agente privado e os benefícios almejados. Neste caso, a corrupção é sempre uma interação entre um agente público e um agente privado, e as vantagens, são sempre privadas. Estas definições não conseguem absorver os casos de corrupção onde ambos os agentes são públicos, ou as vantagens, não são privados (PAZ, 2014, p. 20)

Sintetizando, a corrupção seja em qual for a esfera (pública ou privada), caracterizasse como um desvio da conduta e dos deveres legais previamente estabelecidos de uma função pública ou privada, que tem por objetivo tomar proveito próprio a fim de satisfazer interesses particulares. Como já foi discutido anteriormente, a prática da corrupção é entendida como toda e qualquer ação de atores sociais que desafiam a legalidade, institucionalidade, dos sistemas jurídicos, sociais, políticos, econômicos, previamente estabelecido para a ordem social, e que acabam por lesar o interesse público em detrimento do interesse particular. 
A corrupção interfere na harmonia social, econômica, e política de uma nação, estado ou município, e até mesmo em esferas reduzidas a sociedade civil que com o ato de corromper ou adquirir favores e vantagens de forma ilegal, podem e alteram a ordem estabelecida pelas leis positivadas e regras sociais intrínsecas que partem de um contrato social moral e eticamente entranhados nos seres humanos, uma vez que se identifiquem como cidadãos pertencente a uma comunidade.

Desta forma a corrupção traz consigo, além de ser por si só um problema entranhado nas diversas instâncias do Estado, outras mazelas sociais, que interferem diretamente na economia, e na política, dentre ela podemos destacar:

- Redução da taxa de crescimento econômico: a alta taxa de corrupção em uma nação compromete a confiabilidade de investidores internacionais quanto a aplicação de seus recursos em empresas e ações destes países, que desta forma aumenta a concentração de renda, inibe a criação de postos de trabalho, diminui o consumo e altera o potencial de giro no capital interno, gerando ainda desigualdade social, e concentração de renda;

- Minimiza a legitimação do governo: um Estado onde o nível de corrupção é elevado diminui a confiabilidade dos cidadãos em seu governo e na sua capacidade de gestão dos recursos arrecadados, torando a sociedade um tanto quanto insegura, e vulneráveis conflitos sociais e políticos violentos.

- Altera os gastos públicos: neste quesito a corrupção desvia recursos que teriam a finalidade de atender as necessidades básicas dos cidadãos, para atender a interesses particulares, resultado disso, são hospitais sucateados, escolas em péssimas condições, rodovias malconservadas, a segurança pública em um estado de insegurança pública, entre tantos outros problemas decorrentes a má gestão do dinheiro público.

- Inibe o investimento privado: como descrito no primeiro item desta relação, a corrupção reduz a capacidade e a confiança dos agentes privados em investirem capital e recursos humanos nas empresas, uma vez que estes sentem-se ameaçados pela concorrência desleal decorrente do favorecimento e clientelismo de um governo corrupto. E neste quesito, englobam ainda o investimento estrangeiro, que não vê perspectivas de retorno ao investir em países corruptos.

Em síntese, podemos observar que a alta taxa de corrupção desencadeia um "efeito dominó" nas três principais relações que organizam a sociedade, ou seja, a vida social, econômica e política, e neste sentido, afeta diretamente a alocação de gastos governamentais, o que favorece ainda mais a capacidade de ações corruptas no seio do Estado e leva assim a redução da arrecadação (tributos e outras contribuições ao Tesouro Nacional), devido ao descrédito dos investidores e empresários sendo estes os agentes fomentadores da economia nacional.

Em um ambiente corrupto, muitas empresas veem-se obrigadas a ingressar na economia informal, pela impossibilidade de concorrência e pela não aceitação de pagamento, por exemplo, de propinas Esta impossibilidade de concorrência pode gerar uma menor eficiência na fabricação de produtos e serviços, além da redução da existência de pequenas empresas, prejudicando a taxa de crescimento da economia, visto que, na maioria das economias, as pequenas empresas consistem no "motor" do crescimento (SILVA; BRAGA; LAURENCEL, 2009, p. 105)

Prosseguindo neste caminho, reduz os postos de trabalho, o que acarreta desemprego, concentração de renda, desigualdade social, violência, baixa rotatividade da economia, se tornando um ciclo vicioso e de péssimas consequências para o país. 
[...] a corrupção prejudica o desenvolvimento econômico e político, e compromete a eficiência e a eficácia administrativa. Ela põe em xeque a legitimidade das instituições e dos líderes políticos, pois desmoraliza a liderança de um país e reduz a capacidade do governo de confiar na cooperação e no apoio e participação popular. O resultado disso pode ser instabilidade política e inquietação social que inibem o desenvolvimento e podem gerar reações violentas (ORTH; ALVES, 2012, p. 87).

A corrupção principalmente quando afeta altos escalões públicos e em grande escala, torna-se uma ameaça ao Estado democrático e ao Estado de Direito em qualquer país, seja desenvolvido, em desenvolvimento ou subdesenvolvido, neste sentido, corrupção prejudica diretamente e de forma negativa a prestação de contas dos governos, desestimula os investimentos estrangeiros, problematiza o desempenho econômico e reduz a confiança nos sistemas legal e jurídico, sendo assim, destrói o Estado de Direito e a transparência do governo, limitando o progresso de um país, além de gerar instabilidade política e econômica.

Dentro do conceito de corrupção podemos identificar ainda duas formas que ela se manifesta, corrupção passiva e ativa.

Por corrupção passiva entendemos a partir do Código Penal Brasileiro em vigência, no livro XI em seu título dos Crimes Contra Administração Pública e em seu artigo 317 que dizer se caracterizar em "solicitar ou receber, para si ou para outrem direta ou indiretamente, ainda que fora da função, ou antes, de assumi-la, mas em razão dela. Pena de reclusão de um a oito anos e multa". Estes crimes são cometidos geralmente por servidores públicos que ganham direta ou indiretamente benefícios, ou a promessa dos mesmos.

Já a corrupção ativa é o ato praticado por particulares contra a gestão pública, consiste na possibilidade de proporcionar e/ou agenciar vantagem para servidores públicos, para estabelecê-la como prática, omissão ou atraso de ato de oficio. Assim o mesmo artigo 317 do Código Penal Brasileiro, reza que, recai sobre o interesse de se preservar o normal funcionamento e o prestigio da Administração pública, a sua respeitabilidade e a integridade dos funcionários.

Para melhor compreensão, vamos interpelar a discussão a partir de um olhar mundial de combate a corrupção tendo na Organização das Nações Unidas sua instância maior, sendo que foi em 2005, em uma negociação que durou dois anos, e reuniu representantes de mais de 130 países, emerge a partir de então um acordo para o combate à corrupção.

A Convenção das Organizações das Nações Unidas contra a Corrupção (Unac) é considerada um momento histórico para a tentativa de extermínio da corrupção. Esta convenção escolhe alguns tópicos de outras convenções, por exemplo, os ajusta e os transforma em um conjunto abrangente de compromissos (SILVA; BRAGA; LAURENCEL, 2009, p. 107).

Em diversos países foram desenvolvidos tratados, acordos, convenções, propostas e princípios visando à implementação da Convenção das Organizações das Nações Unidas contra a Corrupção (Unac).

Há um esforço de diversos países em diminuir ao máximo o nível de corrupção, contemplando em suas legislações punições criminais para quem infringe as leis, a moral e a ética no setor público, muito embora a tentativa de coibir a corrupção nos diversos países e em especial no Brasil tem sido um tanto quanto ineficientes, apesar de termos nos últimos anos, 
inúmeros casos escandalosos de corrupção, que bom ou mal, o fato é que as investigações tem intensificado, e trazendo à tona casos que existiam há anos.

No que se refere ao setor público, as reformas compreendem a reorganização e o fortalecimento do funcionalismo público, a mudança no comportamento dos líderes políticos e a criação de órgãos, conselhos e comissões específicas para tratar do controle e do combate à corrupção (ORTH; ALVES, 2012, p. 93).

Alguns dos mecanismos para desarticular a corrupção é o fortalecimento do funcionalismo público através do potencialização das funções e capacitação profissional, e isso é oriundo de treinamento e seleção, conhecimento cientifico e teórico para tornar o desempenho do serviço público mais eficiente e eficaz, outro ponto a ser considerado é a questão da remuneração, ou plano de cargos e salários, trabalhadores bem remunerados, são mais motivados e satisfeitos, e atrelado a isso, a meritocracia no conceito de desempenho das funções, "o controle sobre a propina dependerá, em grande parte, da restrição moral de cada político à mesma e do interesse público com relação ao comportamento político" (SILVA, 1995, p. 42).

Um modelo estratégico e prático para o combate a corrupção no Brasil não é fácil devido suas particularidades e sua dimensão territorial, mas para além disso descrevemos abaixo alguns outros pontos que podemos analisar para um efetivo combate a corrupção, entre elas estão:

- Envolver pessoas na formulação de políticas: a participação social é um ponto crucial para o combate a corrupção, uma vez que os cidadãos comuns, mas engajados na política setorial ou nacional, podem através de sua participação, fiscalizar mais próximo dos legisladores e executores de políticas, como estão sendo utilizados os recursos financeiros do Estado;

- Informatização do setor público: é através deste quesito que a transparência pública se consolida, e os regimes administrativos tornam-se mais claros, pois pode-se consultar os relatórios e orçamento com maior facilidade;

- Despesas públicas: seguindo o raciocínio o item anterior, as despesas públicas adquirem características mais responsáveis e efetivas, acreditando que a gestão pública possa administrar com senso moral e ético os recursos do Estado;

- Licitações e processo de compra e contratação de serviços para o setor público mais simples: nisto consiste a desburocratização do setor de comprar do Estado, facilitando o contato entre o vendedor ou prestador de serviços com a administração pública.

O Poder Judiciário também tem importância no combate a corrupção e neste sentido, Avritzer e Filgueiras (2011, p. 25) destacam que,

em relação à atuação do Poder Judiciário no controle da corrupção no Brasil, sua atuação tem se pautado como representante funcional da sociedade civil, mas sua estratégia interna de prosseguimento dos casos de corrupção sai da esfera cível em direção à esfera criminal. Isso ocorre, sobretudo, porque não é possível pensar a atuação do Judiciário no Brasil sem a atuação do Ministério Público (MP). Podemos considerar, nesse sentido, que o processo de judicialização da política no Brasil decorre de uma atuação proativa não apenas do Judiciário, mas também do MP, que, apesar de ser uma instituição autônoma e fortemente vinculada ao Poder Executivo, é parte integrante do sistema de Justiça, em sentido mais amplo. 
O Ministério Público também desencadeia papel importante para o combate a corrupção, papel este de investigação direta e tem a responsabilidade de introduzir o importante conceito de criminalização da corrupção no país, o tratando ainda como crime organizado, sendo evidenciado no caso do mensalão, destacado na denúncia do Inquérito no 2.245 da Procuradoria-Geral da República, que afirmou a existência de uma "sofisticada organização criminosa, dividida em setores de atuação, que se estruturou profissionalmente para a prática de crimes como peculato, lavagem de dinheiro, corrupção ativa, gestão fraudulenta, além das mais diversas formas de fraude" (BRASIL, 2006).

Outro fator importante, e que é o objeto deste trabalho é questão da contabilidade e o seu papel no controle da corrupção tendo na auditoria linha auxiliar para o administrador na tomada de decisões, por meio de relatórios, balanços, e pareceres, além de colaborar na evidenciação de erro, omissão ou fraude, salvaguardando o patrimônio da instituição e neste sentido, Castro e Garcia (2004, p. 86) dizem que "a auditoria precisa atuar validando e dando credibilidade aos dados divulgados, tornando-se responsável por controlar a qualidade dos mesmos. Aí está o papel do controle interno e da auditoria”. E este é o ponto a ser discutido a seguir.

\section{CONTABILIDADE E AUDITORIA NO COMBATE À CORRUPÇÃO}

A contabilidade tem por objetivo estabelecer justiça e confiabilidade nos registros que utilizam suas regras e pressupostos, bem como suas técnicas e práticas que perpassam pelos princípios fundamentais e pelas normas contábeis brasileiras, seja em instituições públicas ou em organizações privadas, mas que podem trazer luz sobre a situação econômico-financeira do patrimônio das instituições e empresas, e demonstrar os resultados do período administrativo examinado e as demais situações nelas apresentadas.

A contabilidade é uma ciência aplicada com metodologia especialmente concebida para captar, registrar, acumular, resumir e interpretar fenômenos que afetam situações patrimoniais, financeiras e econômicas de qualquer ente, seja este uma pessoa física, jurídica, entidade de finalidades não lucrativas, empresas, do direito privado ou público, tais como: Estado, Municípios, União, autarquias e fundações, entre outros (MATIAS-PEREIRA, 2018, p. 255).

Os utilizadores das informações contábeis são diversos, mas entres alguns, podemos destacar que os principais são, administradores, funcionários em geral que necessitem de informações contábeis para desenvolver suas atividades, os órgãos governamentais de cunho fiscalizadores ou financiadores, bancos e outros agentes econômicos, entre outros. "Os trabalhos de auditoria, geram um resultado único, intangível, pois apresenta recomendações às demais unidades da organização por meio do Relatório de Auditoria" (Leite e Costa, 2018, p. $5)$.

As informações contábeis precisam ser críveis, pois, as consequências que delas se originam podem ser decisivas para as empresas, uma vez que servem de apoio para a liberação de recursos financeiros, por bancos e instituições financeira, pois é nas demonstrações contábeis que está explicito o diagnóstico financeiro das empresas, e neste sentido podemos estabelecer quatro pontos básicos.

1) A informação contábil pode afetar a distribuição de riqueza entre investidores. Essa consequência decorre do fato de que os investidores mais 
bem informados podem aumentar a sua riqueza às custas de investidores menos informados;

2) A informação contábil pode afetar a percepção dos coeficientes de risco e sua distribuição entre os agentes econômicos;

3) A informação contábil pode afetar as taxas de investimentos e consumo em toda a sociedade; $\mathrm{e}$

4) A informação contábil pode afetar a forma pela qual os investimentos são alocados entre as empresas (BEAVER, 1981, p. 50).

Neste sentido, podemos ratificar que os financiadores e fornecedores interpretam as demonstrações contábeis como sendo o diagnóstico da saúde econômica da empresa, ou seja, informações econômicas confiáveis, e por sua vez, a responsabilidade da contabilidade, e a consciência do profissional para fornecer estas informações pode comprometer toda a estrutura organizacional.

Pode-se dizer que, "a auditoria tanto na área pública quanto na área privada é uma especialização contábil voltada a testar a eficiência e eficácia do controle patrimonial, com o objetivo de atestar sua validade sobre determinado dado" (ATTIE, 2000, p. 25), fica clara a importância da auditoria contábil para as contas pública que por fim tem como objetivo ser princípio norteador para o gestor e para sua tomada de decisão.

A auditoria pode ser definida como o levantamento, o estudo e a avaliação sistemática de transações, técnicas, procedimentos, rotinas e demonstrações contábeis de uma entidade, ela confirma a existência do item; mensurá-lo; avaliá-lo; verifica se foi corretamente registrado ou escriturado; propõe os ajustes e as correções que julgar necessárias, de modo a fornecer aos seus usuários uma opinião imparcial e fundamentada acerca das normas e princípios sobre sua adequação (NUNES, 2006, p. 5).

Neste sentido, podemos ainda estabelecer que mediante técnicas e princípios próprios a auditoria é uma ferramenta de controle de gastos públicos, bem como um instrumento poderoso no que diz respeito a prevenção, combate, e identificação de casos de corrupção nas instituições públicas.

Para isso precisamos estabelecer os conceitos básicos da auditoria que podem ser identificadas independentes de qual seja a esfera (pública ou privada) que ela for aplicadas, e estas normatizações são oriundas dos conselhos profissional, sendo atualizados sempre que necessários, mas não antes submetida a debates e discussões de cunho técnico-cientifico para sua aprovação, o que passam a ter designo de normas usuais de auditoria ou normas geralmente aceitas e representam os quesitos a serem observados pelo auditor no exercício das atividades de auditoria.

As normas relativas à pessoa do auditor dizem respeito à qualificação técnica e a postura profissional do auditor. Basicamente, dividem-se em independência, conhecimento técnico, capacidade profissional, cautela, zelo profissional e comportamento ético. As normas relativas à execução dos trabalhos dizem respeito às condições que devem cercar o exame de auditoria. São classificadas em planejamento, avaliação de controles internos, supervisão dos trabalhos, obtenção de evidências, improbidades e irregularidades. As normas relativas à opinião do auditor referem-se aos elementos que devem cercar as opiniões do auditor, expressar por meio de 
relatórios e acompanhadas de parecer ou certificado de auditoria. (LIMA; CASTRO, 2003, pp.28-29)

Desta forma podemos delimitar que as normas de auditoria nada mais são do que regras e normas regulamentadas pelos órgãos que regulamentam a profissão contábil, e que se objetivam por balizar e direcionar o trabalho dos profissionais que tem no seu exercício funcional a auditoria, nestas técnicas exigem do profissional auditor responsabilidade na execução de suas tarefas funcionais bem como lisura e transparência ao expressar relatórios e opiniões profissionais a certa das contas e situação das empresas ou instituições públicas.

Nesta perspectiva, podemos dizer que existem duas formas de auditoria, ou seja, a auditoria interna e externa. Por auditoria interna podemos dizer que é um agrupamento de métodos e técnicas que se objetivam em analisar a integridade, adequação e eficácia dos controles internos e das informações físicas, contábeis, financeiras e operacionais da Entidade, e neste sentido, Nascimento (2004, p. 78) destaca que "as auditorias internas dos órgãos públicos optam pelo improviso, no que se refere à definição de áreas e rotinas a serem examinadas, ao passo que se poderiam elaborar procedimentos de auditoria e papéis de trabalho próprios e aplicá-los com determinada frequência."

O objetivo do auditor interno, precisa em todo o tempo preservar sua autonomia profissional, privando de vícios que possam surgir, protecionismos, presando pela lisura e transparência, isto é, com imparcialidade. Deve ainda zelar pela execução do trabalho e na demonstração dos resultados, conclusões e relatórios pertinentes, bem como manter a ética profissional e prezar pelo sigilo, mesmo após o desligamento profissional com a empresa na qual prestava serviço.

Em síntese, pode se dizer que a auditoria interna consiste em uma atividade de avaliação independente, que atuando juntamente com administradores e especialistas, deverá avaliar a eficiência e eficácia dos sistemas de controle de toda a entidade, zelando pela aplicação das políticas traçadas e provocando melhorias, fornecendo com isso subsídios aos administradores para a tomada de decisão, visando ao cumprimento da missão da entidade (NUNES, 2006, p. 7).

Partindo para o conceito e auditoria externa ou independente, temos para ambas as esferas, públicas ou privadas, uma gama de procedimentos, métodos e técnicas, para a emissão de pareceres e relatórios que examinam a saúde patrimonial e financeira, bem como as origens e destinos das operações financeiras, as mutações patrimoniais, e aplicações de recursos, observando sempre as diretrizes do conselho profissional para a execução da atividade profissional.

No que se refere a auditoria pública ou a nível de governos, podemos dizer que, "as recomendações do auditor independente afetam diretamente a administração daqueles que ocupam cargos públicos, interessa a estes não as implementar, pois seria o reconhecimento da culpa" (NASCIMENTO, 2004, p. 79). Neste sentido, a auditoria não é bem vista pelos gestores governamentais, pois ela ratifica a corrupção, e explicita a culpa dos corruptores.

Neste sentido as manipulações contábeis podem ser feitas, como o objetivo de apresentar, para os usuários externos, de uma melhor situação financeira e patrimonial da empresa, porém, estes resultados não expressam de fato a realidade da empresa ou instituição, e esta ação pode fomentar os desvios de recursos da empresa para favorecer interesses particulares, e no campo contábil, e estas atitudes nada mais são do que corrupção. 


\begin{abstract}
A utilização de modalidade escritural, capaz de esconder a realidade da movimentação de recursos de uma empresa, realidade essa que importa a caracterização de fatos geradores de tributos, logicamente frustra o controle formal da situação tributária, ensejando a garantia da redução ou da supressão do pagamento da tributação. A fiscalização não tem acesso aos dados reais, que revelariam os fatos imponíveis e, inexistindo o lançamento, opera-se a decadência ou a prescrição, extinguindo-se o crédito tributário. A tutela, pois, é da integridade do erário, indiretamente, e diretamente do poder fiscalizatório regular da Fazenda Pública (ROSA, 2005, p. 23).
\end{abstract}

É um erro associar a corrupção como algo intrínseco ao povo brasileiro, pois não é genético, ou seja, não há em nós genes que determine que nossa população seja ou não corrupta, que traga uma carga genética que nos predisponha à corrupção, não é algo herdado, dos nossos colonizadores portugueses.

Um exemplo claro da afirmação acima é o caso da Austrália que teve em sua colonização o objetivo de abrigar criminosos britânicos, e isso não faz desta nação mais corrupta que outros países, outro exemplo que podemos citar, é o caso japonês que não poucas vezes estampam manchetes de jornais com escândalos de corrupção, o que diferencia é o tratamento dado pela legislação destes países aos corruptores, tendo severidade e punição cabíveis aos corruptos.

Outro ponto a se considerar, é o papel da mídia nos casos de corrupção no Brasil, esta muitas vezes tendenciosa e não menos corrupta, manipula informações e privilegia seus aliados, e neste sentido, os escândalos que hoje nos são estarrecedores e têm em muito o credito do Ministério Público e da Policia Federal que passaram a ter autonomia política e institucional para a investigação, fato este que anteriormente não existia.

O Ministério Público, como instituição garantidora do princípio constitucional da moralidade administrativa, deve combater à improbidade, investigando os corruptos e os corruptores, buscando a sua punição e zelando pela promoção do direito fundamental a governos honestos, como corolário do regime republicano. O Ministério Público possui instrumentos operacionais, como o inquérito civil e a ação civil pública, para defesa e garantia do patrimônio público e social, do meio ambiente e de outros interesses difusos (CAMBI, 2014, p. 15)

No Brasil existe sim corrupção, seja no âmbito das instituições públicas ou privadas, muito embora apenas seja percebida quando sua importância chega aos milhões de dólares e porque um irmão, um genro, um jornalista ou alguém botou a boca no trombone, não por um processo sistemático de auditoria, ou seja, não por que houve uma investigação criteriosa e com lisura.

Nos países onde os índices de corrupção são menores, pode se perceber que a preocupação com a prevenção é relevante e tem nos auditores e fiscais formados, treinados e capacitados, seus pontos fortes, neste sentido, podemos exemplificar com os casos da Dinamarca e a Holanda, países estes que tem cerca de 100 auditores para cada 100.000 habitantes. Nos países comprometidos com a auditoria, a corrupção é facilmente detectada previamente e combatida com eficiência, e este não é o caso do Brasil, que possuí um dos mais elevados índices de corrupção, segundo o World Economic Forum, e possuí ainda cerca de oito auditores por 100.000 habitantes, 12.800 auditores no total, para que alcancemos os níveis de transparência de Dinamarca e da Holanda precisaremos formar e treinar ainda cerca de 160.000 auditores. 
A Auditoria nada mais é do que um ramo da Contabilidade, e esta é inserida na esfera pública brasileira, ou seja, a Contabilidade Pública é autorizada e regulamentada pela Lei $\mathrm{n}^{\circ}$ 4.320/64, e tem no artigo 83 sua determinação base, que reza "a contabilidade evidenciará perante a Fazenda Pública a situação de todos quantos, de qualquer modo, arrecadem receitas, efetuem despesas, administrem ou guardem bens a ela pertencentes ou confiados", portanto, merece sublinha que a contabilidade pública não pode ser percebida com a finalidade apenas de registrar e escriturar, antes disso, é também à observação da legalidade dos atos da execução orçamentária, controladoria e acompanhamento, e isso deve ser previsto, concomitante e subsequente.

[...] a contabilidade pública possui um importante papel frente à sociedade, cabendo a ela a demonstração exata dos atos e fatos atinentes à gestão pública, evidenciando de forma precisa e acessível a todo cidadão as ações governamentais, cumprindo sua finalidade de ciência social. (MENDES; OLEIRO; QUINTANA, 2008, p. 42)

Umas das principais preocupações da contabilidade deve ser formar pessoal capacitado para exercer a função de auditores e controladores, que sejam responsáveis e competentes para executar dentro das instituições do Estado o papel fiscalizador, inibindo desta forma fraudes, desvios e todos os tipos de corrupção possíveis de serem praticadas.

Platt Neto et al. (2007, p. 75), diz que "[...] mais do que garantir o atendimento das normas legais, as iniciativas de transparência na administração pública constituem uma política de gestão responsável que favorece o exercício da cidadania pela população", por isso a participação social recebe destaque na transparência pública também.

Antes da redemocratização, e vivendo o auge do período militar, a liberdade de imprensa e a auditoria não eram priorizadas e muitas vezes reprimidas, e com isso recursos destinados a formação de profissionais da contabilidade e auditoria tomaram outros rumos, e como consequência, foi reduzida drasticamente a participação destes profissionais no âmbito do Estado. É necessário e urgente que para acabarmos com a corrupção no Brasil teremos que nos preocupar com a formação profissional e financiar investigação cientifica objetivada em criar e aperfeiçoar métodos de trabalho eficientes e práticos de implementação para gerir e fiscalizar os recursos do Estado.

Mendes, Oleiro e Quintana (2008, p. 42) destacam que, "assim como a Contabilidade, a Auditoria tem importante função dentro da administração pública, incumbindo a ela a emissão de opinião sobre os demonstrativos contábeis exigidos pela Lei $n^{\circ} 4.320 / 64$ ", neste sentido, auditoria governamental contempla um campo de especialização da contabilidade e é direcionada à Administração Pública (Direta e Indireta), compreendendo desta forma a auditoria interna e externa, envolvendo diretamente o patrimônio e/ou o interesse público, bem como o orçamento.

Em países desenvolvidos se coloca os auditores em destaque e respeitabilidade, com reconhecimento público para garantir a lisura e a sua honestidade, é o caso da Inglaterra, que tem Chartered Accountant como instituição de representatividade, e nos Estados Unidos se destaca o Certified Public Accountant, para a sociedade inglesa e americana é um sonho as famílias terem um filho médico, advogado ou contador público, enquanto isso no Brasil, o contador público foi substituído pelo engenheiro.

Um dos fomentadores da corrupção é a falta da valorização profissional, através de bons salários e reconhecimento social dos trabalhadores, neste sentido, podem ser requisitos básicos para o funcionamento do sistema público, porém a realidade brasileira é bem diferente deste posto, remuneramos mal nosso auditores e não reconhecemos o papel fundamental que 
eles desempenham no âmbito da fiscalização e da auditoria das instituições públicas, nem se quer os treinamos e os capacitamos de fato, comprometendo o futuros auditores, da profissão e dos órgãos públicos.

Castro e Garcia (2004, p.42) ressaltam o objetivo da visão contábil dizendo que

[...] na visão objetiva, a informação produzida pela Contabilidade é a que oferece maior credibilidade, não só pelo fato de a informação ter na base um documento que a suporta, mas principalmente, por ter um profissional que por ela se responsabiliza e que poderá ser penalizado caso esteja incorreta.

Diante de tamanha responsabilidade do contador que exercer a função de auditoria e fiscalização, o exposto acima é de grande preocupação pois, pessoas que exercem funções de responsabilidade financeiras e fiscal, que tem má remuneração tem uma propensão de corrupção maior, além de não fazer a atividade atrativa para jovens profissionais.

A Contabilidade pode ser compreendido como o filtro inicial do enfrentamento a corrupção, pois todas as informações administrativas contabilizáveis passam por crivo e registro contábeis e fiscais pertinentes, sendo de responsabilidades dos departamentos especifico, passando por constantes analises e estudos para verificar o posicionamento das contas públicas partido dos princípios contábeis, da legalidade, da legitimidade, da veracidade e da idoneidade dos documentos.

Um outro aspecto a ser colocado em relação ao sistema de contabilidade é que com o advento da Lei de Responsabilidade Fiscal (LRF) os órgãos centrais de contabilidade governamental, no caso do Governo Federal esse órgão é a Secretaria de Tesouro Nacional (STN), passaram a divulgar, inclusive por meio eletrônico (internet) os Relatórios Resumidos da Execução Orçamentária (arts. 52 e 53 da LRF) e os Relatórios de Gestão Fiscal (arts. 54 e 55 da LRF), dando transparência à sociedade acerca da gestão pública. Vejamos o art. 48 da LRF:

\footnotetext{
Art. 48. São instrumentos de transparência da gestão fiscal, aos quais será dada ampla divulgação, inclusive em meios eletrônicos de acesso público: os planos, orçamentos e leis de diretrizes orçamentárias; as prestações de contas e o respectivo parecer prévio; o Relatório Resumido da Execução Orçamentária e o Relatório de Gestão Fiscal; e as versões simplificadas desses documentos.

Parágrafo único - A transparência será assegurada também mediante incentivo à participação popular e realização de audiências públicas, durante os processos de elaboração e de discussão dos planos, lei de diretrizes orçamentárias e orçamentos.
}

Sentenciado no exposto acima, a corrupção tem sido manchetes nos jornais e em todos os meios de comunicação, e mediante as discussões e debates com referencial teórico criteriosamente selecionados, temos a percepção que a corrupção é uma mazela da sociedade e que acentua ou ainda, causa outros problemas estruturais para a vida social. Neste sentido, "a democracia é fortalecida quando o cidadão recebe essa prestação de contas por parte dos agentes públicos, pois a informação gera posicionamento, que e é o primeiro passo para a participação do povo nas decisões públicas" (FERNANDES; BORGES; LEITE JÚNIOR, 2017, p. 647).

A corrupção por sua vez não é exclusividade do Brasil, ela está presente nos mais variados países e modelos de governação, e que mediante Nações Unidas tem vem buscando 
alternativas e medidas para enfrentar este grave problema que acaba por comprometer todo o desenvolvimento da sociedade seja nos níveis econômicos, políticos e sociais.

\section{CONSIDERAÇÕES FINAIS}

Não era o propósito deste trabalho estabelecer conclusões e veredictos sobre as categorias de analises aqui propostos, antes disso, era proporcionar a reflexão e fomentar a argumentação, além de estabelecer a discussão teórica metodologia com autores e pensadores que já antes se debruçaram sobre o assunto, e a nós, cabe acrescentar o que percebemos do assunto.

Há quem diga que não é papel do Estado suprir alguns serviços públicos como o caso da produção de petróleo, mas é inegável a participação do Estado na regulação e fiscalização da produção, e comercialização dos produtos que derivam do produto primário, garantindo ao consumidor de estar a comprar produtos de boa qualidade e livre de falsificação. Não serão medidas radicais que irão resolver o problema da corrupção no Brasil, antes disso, precisamos de um nível de educação, para que desenvolva na sociedade um senso ético e moral, que os livre deste problema, o que garanta também igualdade de condições a todos os cidadãos.

Talvez este seja o sistema imunológico que necessitamos, e vemos na auditoria este potencial de sentinela a zelar pela lisura e transparência das contas e gastos públicos, associados com a participação do cidadão, não apenas quando os escândalos surgem e impactam a sociedade, seguindo os modelos de países considerados honestos e bem auditados. Neste sentido, o Brasil não pode ser considerado como um país corrupto, antes disso, é um país mal auditado, e que desta forma compromete todo o desenvolvimento social, econômico e político.

A auditoria representa instrumento legal, e potente para combater, e para isso é necessário investimento na formação profissional, cientifica e metodológica, aliada com bons salários e reconhecimentos social e prestigio profissional, além da atratividade para jovens estudantes a ingressarem na profissão.

Através do debate proposto podemos verificar que a corrupção gera prejuízos econômicos, além de levar o cidadão ao descrédito governamental, desestimula os investimentos empresariais, o que leva a instabilidade nos ambientes de negócio, enfraquecendo a economia, e entre mais podemos dizer que os desvios causados pela corrupção acarretam ainda, desigualdades econômicas motivadas pelas competições desonestas.

A corrupção agrava os problemas sociais, pois os serviços públicos deixam de receber recursos pois estes são desviados, e seguindo este argumento percebemos que escolas são sucateadas porque gestores públicos utilizam as verbas destinadas as reformas e manutenção das mesmas, em outras obras, ou superfaturando, e desta forma a sociedade perde. Este é apenas um exemplo dos vários que podem ser citados, na saúde, na segurança pública, na mobilidade urbana, na assistência social.

Mas não se pode afirmar que apenas a nível de Estado e instituições ligadas ao Estado encontramos a corrupção, ela está presente em nossas vidas, no nosso cotidiano, quando tentamos furar uma fila para sermos atendidos antes, quando oferecemos gratificação para nosso processo no interior de uma prefeitura seja privilegiado, quando contratamos uma doméstica e não assinamos sua carteira.

A corrupção é sim um problema nacional, mas deve ser combatido individualmente, passar pelo caráter da moral particular, e isso vem com a educação, não apenas a educação formal, mas a educação que procede nos seios das famílias. 


\section{REFERÊNCIAS}

ATTIE, W. Auditoria Conceito e Aplicação. São Paulo: Atlas S.A., 2000.

AVRITZER, L.; FILGUEIRAS, F. Corrupção e controles democráticos no Brasil. Brasília, DF: CEPAL. Escritório no Brasil/IPEA, 2011.

BEAVER, W. Financial reporting: an accounting revolution. Englewood Cliffs, NJ: Prentice Hall, 1981.

BRASIL. Lei $\mathrm{n}^{\mathrm{o}} 4.320$, de 17 de março de 1964. Disponível em: http://www.planalto.gov.br/ccivil_03/Leis/L4320.html Consultado em: novembro de 2018.

.Denúncia no Inquérito no 2.245. Brasília: Procuradoria-Geral da República. Inquérito no 2.245. Brasília: Procuradoria-Geral da República, 2006.

CAMBI, E. A atuação do Ministério Público no Combate a Corrupção na Lei 12.846/2013. In. Revista do Conselho Nacional do Ministério Público/ Comissão de Jurisprudência. Conselho Nacional do Ministério Público. Brasília. CNMP, n. 4, 2014.

CASTRO, D. P. de; GARCIA, L.M. Contabilidade Pública no Governo Federal. São Paulo: Atlas, 2004.

CHAUÍ, M. Convite à Filosofia. São Paulo: Ática, 2000.

FERNANDES, L. D. L. F.; BORGES. T. J.; LEITE JÚNIOR, M. C. R. Auditoria e Controle Interno no Setor Público e Sua Contribuição para a Democracia. Revista da Universidade Vale do Rio Verde, v. 15, n. 1. Três Corações - MG. jan./jul. 2017.

GIL, A. C. Métodos e técnicas de pesquisa social. São Paulo: Atlas, 2006.

LEITE, P. S. O.; COSTA, A. J. B. Estimativa e Monitoramento dos Custos por Trabalho: Estudo de caso em auditoria no Setor Público. Revista da Universidade Vale do Rio Verde. Vol. 16. n. 2. Três Corações - MG, 2018.

LIMA, D. V.; CASTRO, G. Fundamentos de Auditoria Governamental e Empresarial. São Paulo: Atlas S.A., 2003. 138 p.

MATIAS-PEREIRA, J. Administração Pública: foco nas instituições e ações governamentais. 5.ed. ver. E atual. São Paulo: Atlas, 2018.

MENDES, R. C.; OLEIRO, W. N.; QUINTANA, A. C. A contribuição da contabilidade e auditoria governamental para uma melhor transparência na gestão pública em busca do combate à corrupção. <http://www.congressocfc.org.br/hotsite/trabalhos_1/214.pdf>. Acesso em: 16 dez. 2014.

NASCIMENTO, R. S. Aspectos Relevantes da avaliação dos controles internos na auditoria governamental. Revista Brasileira de Contabilidade. São Paulo, v.33, n¹47, p. 65-81, maio/junho 2004. 
NUNES, J. de O. Auditoria pública e privada: uma análise comparativa. Santa Maria: Revista Eletrônica de Contabilidade, Vol. III, n. 1, jan-jun, 2006.

ORTH, C. F.; ALVES, T. W. Perspectivas de inibição da corrupção a partir da carta compromisso do governo gaúcho: um enfoque econômico. São Paulo: Revista Política Hoje, Vol. 21, n. 1, 2012.

OLIVEIRA, R. R. Contabilidade, controle interno e controle externo: trinômio necessário para combater a corrupção. Disponível em: http://www.atena.org.br/revista/ojs-2.2.308/index.php/pensarcontabil/article/viewFile/39/39

PAZ, E. M. A corrupção no Brasil atual conforme a percepção de empresários brasileiros. 2014.

PLATT NETO, O.; CRUZ, F.; ENSSLIN, S. R.; ENSSLIN, L. Publicidade e Transparência das Contas Públicas: obrigatoriedade e abrangência. Revista Contabilidade Vista \& Revista, Belo Horizonte, v.18, nº 1, p.75-94, jan.-mar. 2007.

RICHARDSON, R. J. Pesquisa Social: métodos e técnicas. 4.ed. rev. atual. e ampl. São Paulo: Atlas, 2017.

ROSA, F. B. O caixa dois. Caderno de Direito Penal, v. 1, n. 2, Escola da Magistratura do TRF da $4^{\text {a }}$ Região, 2005. Publicado originalmente na Revista do TRF $4^{a}$ R., n. 51, 2004.

SANTOS, L. A. Reforma Administrativa no Contexto da Democracia. Brasília: DIAP/Arko Advice Ed. 1997.

SILVA, M. F. G. Corrupção e desempenho econômico. In. SPECK, B. W. et al. Os Custos da Corrupção. Caderno Adenauer, Fundação Konrad Adenauer, nº 10, São Paulo, 2000. P. 63-77.

SILVA, A. M. C.; BRAGA, E. C.; LAURENCEL, L da C. A Corrupção em uma Abordagem Econômico-Contábil e o Auxílio da Auditoria como Ferramenta de Combate. Belo Horizonte - MG: Revista Contabilidade Vista \& Revista. Universidade Federal de Minas Gerais, v. 20, n. 1, p. 95-117, jan./mar. 2009. 